\title{
Correction to: PVDF nanofibers obtained by solution blow spinning with use of a commercial airbrush
}

\author{
Gabriel C. Dias ${ }^{1}$ (D) $\cdot$ Thelma S. P. Cellet $^{2} \cdot$ Mirian C. Santos $^{3} \cdot$ Alex O. Sanches $^{1} \cdot$ Luiz F. Malmonge $^{1}$
}

Published online: 27 August 2019

(C) The Polymer Society, Taipei 2019

\section{Correction to: Journal of Polymer Research (2019) 26: 87} https://doi.org/10.1007/s10965-019-1731-7

The original version of this article unfortunately contained a mistake. In Table 1 of the published online paper, there are four commas (,) that must be changed to periods (.). The correct Table 1 is now shown here:

Table 1 Flow rate for different solutions employed airbrush at 5 Bar

\begin{tabular}{ll}
\hline Solution/solvent & Flow Rate \\
\hline Álcohol & $5.17_{\times} 10^{-3} \mathrm{~m}^{3} / \mathrm{s}$ \\
Water & $7.21_{X} 10^{-3} \mathrm{~m}^{3} / \mathrm{s}$ \\
DMF & $6.73 \times 10^{-3} \mathrm{~m}^{3} / \mathrm{s}$ \\
Acetone & $13.2 \times 10^{-3} \mathrm{~m}^{3} / \mathrm{s}$ \\
PVDF/DMF (20\%) & $5.92 \times 10^{-4} \mathrm{~m}^{3} / \mathrm{s}$ \\
\hline
\end{tabular}

Publisher's note Springer Nature remains neutral with regard to jurisdictional claims in published maps and institutional affiliations.

The online version of the original article can be found at https://doi.org/ 10.1007/s10965-019-1731-7

Gabriel C. Dias

gabriel.fct@gmail.com

1 Universidade Estadual Paulista (UNESP), Faculdade de Engenharia, Ilha Solteira, Av. Brasil Sul, 56 - Centro, Ilha Solteira, SP 15385-000, Brazil

2 Universidade Estadual de Maringá(UEM), Departamento de Química, Maringá, PR, Brazil

3 Universidade Estadual Paulista (UNESP), Instituto de Química, Araraquara, SP, Brazil 